\title{
Natureza poligenética de latossolo Bruno em patamares extensos no meio oeste Catarinense - Planalto das Araucárias
}

\author{
Polygenetic nature of latossolo Bruno in extensive levels in the middle \\ west Catarinense - Araucária Plateau
}

\author{
Mayara Cristina Gaspari'; Marga Eliz Pontelli"; Vitor Hugo Rosa Biffi Correio"I
}

\begin{abstract}
RESUMO
O presente trabalho tem como objetivo verificar a natureza dos materiais nos patamares extensos no meio oeste catarinense - Planalto das Araucárias. Para isto, seguiram-se etapas de campo, a fim de caracterizar e levantar as características macromorfológicas que compõem a cobertura superficial, bem como coleta dos materiais, seguidas de etapas laboratoriais, sendo elas: análise granulométrica, densidade do solo e das partículas para determinar a porosidade total, química de rotina, ataque sulfúrico, mineralogia da fração argila, razões $\mathrm{Fe}^{d}$, $\mathrm{Fe}^{\circ}$ e $\mathrm{Fe}^{\mathrm{t}}$, química total e micromorfologia. A seção descrita apresentou 10,50 metros de material, dos quais 4 correspondem ao solum, 1 à aloterita e 5 à isoalterita, totalizando 10 horizontes pedológicos. De forma geral, as análises laboratoriais apontam avançada evolução pedogenética do material, com características correspondentes a LATOSSOLO BRUNO Distrófico, caráter alítico, além de minerais neoformados, por processos de mono e bissialitização concomitantes com minerais formados em condições distintas das atuais, permitindo uma primeira interpretação de solo poligenético. Alterações ambientais de uma fase mais seca e fria para uma fase úmida modificaram a estrutura do horizonte Bw, causando desmantelamento dos peds em estrutura de blocos para granular, mas não alterou o processo pedogeoquímico.
\end{abstract}

Palavras-chave: Latossolo; micromorfologia; DRX

\begin{abstract}
The present work has as objective to verify the nature of the materials in the extensive levels in the middle of Santa Catarina - Araucária Plateau. To this, stages of the capping were followed in order to gather the macromorphological characteristics of the materials which compose the superficial coverage, as well as a collection of materials, afterwards, lab analysis were performed, as follows: particle size analysis, soil and particle density to determine the total porosity, routine chemical analysis, sulfuric attack, mineralogy in clay fraction, the ratios $\mathrm{Fe}^{\mathrm{d}}, \mathrm{Fe}^{\circ}$ and $\mathrm{Fe}^{\mathrm{t}}$ measurement, total chemistry, and lastly, micromorphology. The described section presents $10.50 \mathrm{~m}$ of material, of which 4 correspond to solum, 1 to alloalterite and 5 to isoalterite, totaling 10 pedological horizons.In general, the laboratory analyzes point to pedogenic development of the material, with characteristics corresponding to LATOSSOLO BRUNO Nitossolic distrophic, allytic character, in addition to neoformed minerals, by processes of mono and bissialitization concomitant with minerals formed under different conditions of the current, allowing a first interpretation of polygenetic soil. Environmental changes from a drier and cooler phase to a modified wet phase to a Bw horizon structure, causing dismantling of the peds in block structure to granulate, but did not alter the pedogeochemical process
\end{abstract}

Keywords: Latosol; micromorphology; XRD

Universidade Estadual do Oeste do Paraná (UNIOESTE), https://orcid.org/0000-0002-6250-893X - gasparimayara@gmail.com

Universidade Estadual do Oeste do Paraná (UNIOESTE), https://orcid.org/0000-0002-3921-7923 - mepontelli@hotmail.com

III Universidade Estadual de Maringá (UEM), https://orcid.org/0000-0002-5773-7842 - vhugorosabiffi@gmail.com 


\section{INTRODUÇÃO}

Os Latossolos, classe de solos mais expressiva em distribuição espacial no Brasil, tem ocorrência em regiões com diferentes condições climáticas, relevo e material de origem (MELFI et al., 1979). São solos profundos, muito evoluídos quimicamente, de coloração mais ou menos homogênea, com matizes avermelhadas e/ou amarelas e presença de horizonte diagnóstico B latossólico. Os materiais que constituem os latossolos encontram-se relacionados à intensa intemperização e lixiviação, que promove a remoção das bases e parte da sílica. Esse processo resulta na acumulação relativa de $\mathrm{Al}, \mathrm{Fe}, \mathrm{Si}$ e ocasionalmente $\mathrm{Tl}$, sob a forma óxidos, hidróxidos, e argilominerais filossilicatos 1:1 de baixa atividade (KER, 1997; KAMPF et al., 2012, EMBRAPA, 2014).

Dentro do Sistema Brasileiro de Classificação de Solos, são reconhecidas quatro classes de Latossolos inseridas do segundo nível categórico: LATOSSOLOS BRUNOS, LATOSSOLOS AMARELOS, LATOSSOLOS VERMELHO e LATOSSOLOS VERMELHOAMARELO. Nesse grupo, destacam-se os LATOSSOLOS BRUNO, solos constatados, até a presente data, nos planaltos do Rio Grande do Sul, Santa Catarina, Paraná e na região de Poços Caldas, em Minas Gerais (EMBRAPA, 2006).

Do ponto de vista genético evolutivo, a cobertura Latossólica na região sul do Brasil e, mais especificamente no Planalto das Araucárias, é desenvolvida a partir de materiais tanto de gênese alóctone (DAL-BERTI, 2015; PONTELLI et al., 2015; MANFREDINI, 2016), quanto de gênese autóctone (VOLKMER, 1999; RODRIGUES, 2011, PAISANI et al., 2013, BERTUOL, 2014, PAISANI et al., 2014, GASPARI, 2018; ALMEIDA, 2018), e apresentam diferentes graus de evolução pedogeoquímica. Existem ainda, em determinados casos, coberturas poligenéticas, que são identificadas nesse contexto, a partir de materiais que foram submetidos à ciclos de desenvolvimento diferente das condições ambientais atuais (BRONGER e CATT, 1989; DUCHAUFOUR, 1982, INDA JUNIOR et al., 2005). Esse fato é associado ao processo de etchplanação 
dinâmica que vem atuando na paisagem, sobretudo no Quaternário Tardio (PAISANI et al., 2013).

Embora se reconheça solos poligenéticos nas superfícies de cimeira e superfícies interplanálticas ao longo do Planalto das Araucárias (PAISANI et al., 2019), pouco se sabe sobre a gênese dos Latossolos localizados nos patamares extensos do meio oeste catarinense. Dessa forma, buscou-se entender a gênese dos LATOSSOLOS BRUNOS no contexto mesolocal, utilizando-se de parâmetros físicos, químicos e mineralógicos dos materiais.

\section{2 ÁREA DE ESTUDO}

A área de estudo corresponde ao Planalto da Bacia do Rio Uruguai (PELUSO JR, 1986), disposta na forma de patamares, mais ou menos extensos, e corresponde, do ponto de vista geomórfico, à superfície de Xanxerê, na classe hipsométrica de 701-800 m (PAISANI et al., 2008), inserida no Planalto das Araucárias (Figura 1). A seção descrita está localizada no meio oeste catarinense, no topo de uma colina, em relevo suave ondulado. O substrato rochoso é composto pelas rochas vulcânicas da Formação Serra Geral (NARDY et al., 2008), localmente constituída por rochas do tipo traquito, de natureza ácida, cuja constituição mineralógica ocorre essencialmente por feldspatos alcalinos, como sanidra e ortoclásio e por plagioclásio, como o oligoclásio, podendo ainda admitir a presença de albita em álcali traquitos, biotita, hornblenda, quartzo, anfibólios sódicos e piroxênios em álcali-traquitos (RITMANN, 1973). Em relação ao sistema hidrográfico, a área abriga o sistema de drenagem do rio Chapecó, o qual é drenado por densidade forte de canais que resultam em configuração dendrítica. Os solos da região se apresentam do tipo Nitossolo Vermelho e Latossolo Bruno, ambos com textura muito argilosa e bem drenados (CALDASSO et al., 2002). A cobertura vegetal primária é Floresta Ombrófila Mista, porém, já foi quase completamente substituída pelas atividades rurais, sendo atualmente ocupada por vegetação secundária (IBGE, 2012). O clima regional é do tipo Cfa na classificação de 
Köpeen), mesotérmico, subtropical úmido, com verões quentes, com temperaturas que variam entre 12,4 e $21,1^{\circ} \mathrm{C}$ (MENDONÇA E DANNI-OLIVEIRA, 2007). A pluviosidade está entre 1.790 a 2.280 mm, com total anual de 148 dias de chuvas e umidade relativa anual entre 73 e $82 \%$ (CALDASSO et al., 2002). Essas características de umidade indicam superávit hídrico anual na região.

Figura 1 - Localização do Planalto das Araucárias, Região Sul do Brasil

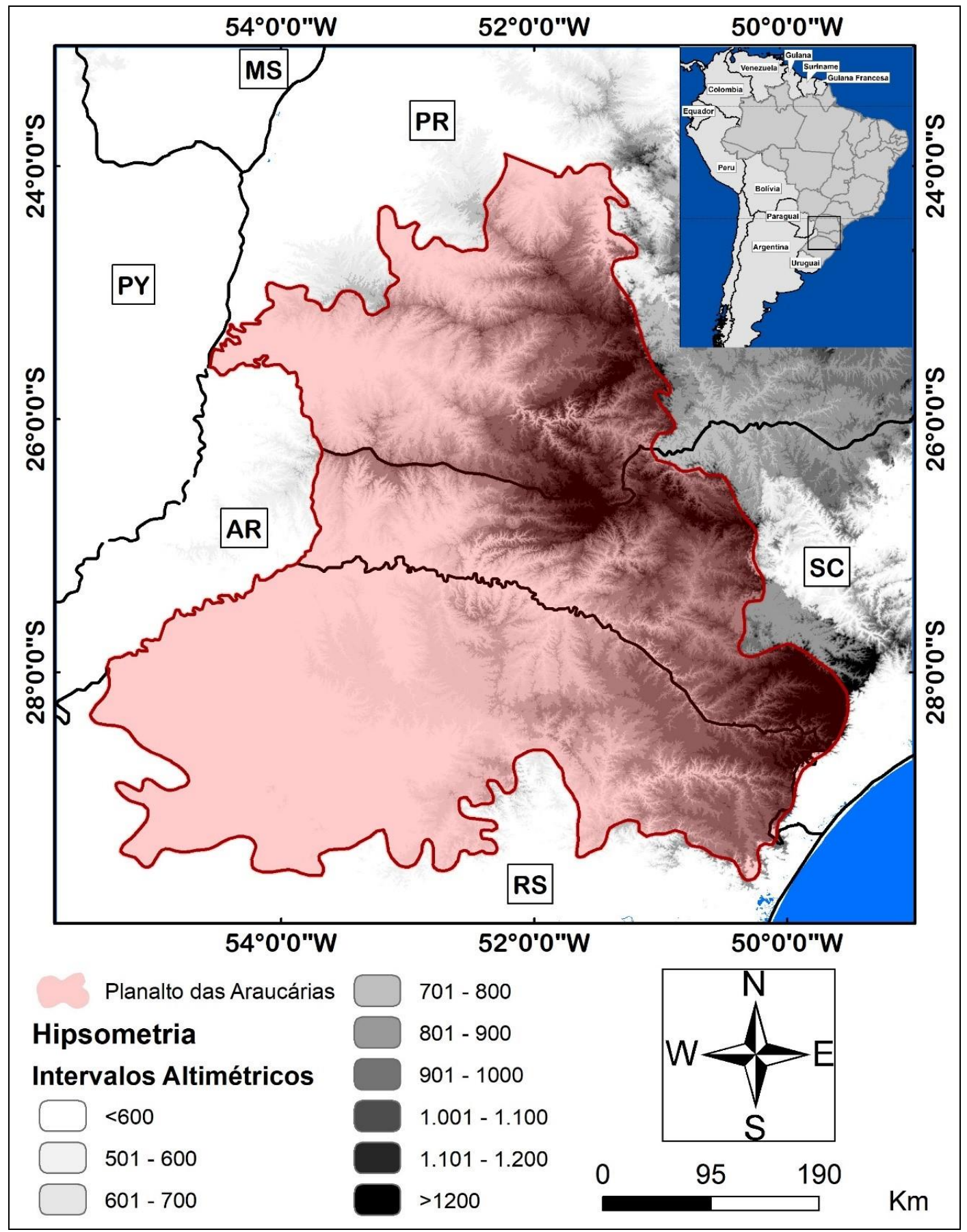

Fonte: Acervo particular dos autores (2018) 


\section{MATERIAL E MÉTODOS}

A fim de definir os processos relacionados à gênese dos materiais dos patamares extensos no meio oeste catarinense, realizou-se a caracterização dos materiais quantos aos aspectos físicos, químicos e mineralógicos. Inicialmente, reconheceu-se o perfil dos materiais exposto em corte de estrada e após a escolha do perfil de intemperismo representativo, procedeu-se a descrição macromorfológica (SANTOS et al., 2005), e realizou-se a coleta das amostras deformadas para os tratamentos granulométricos, química de rotina, química total, ataque sulfúrico, ferro livre total e amorfo e mineralogia, enquanto que para a análise micromorfológica, foram coletadas amostras indeformadas para a confecção das lâminas delgadas conforme procedimentos descritos por Castro (2008). As amostras da granulometria foram realizadas no laboratório de Análises e Formações Superficiais do Campus Unioeste de Francisco Beltrão- PR, a partir de peneiramento para fração grossa $(>0,063 \mathrm{~mm})$ e de pipetagem para fração fina $(<0,063 \mathrm{~mm})$, conforme EMBRAPA (1997). A densidade do solo e das partículas, resultando na porosidade total foi realizada de acordo com os procedimentos estabelecidos pela Embrapa (1997) e as características macromorfológicas, de acordo com os critérios pedológicos proposto por Santos et al., (2005).

A caracterização química e a realização de cálculos para a classificação dos materiais foram obtidas a partir da análise da química de rotina dos macronutrientes, tratadas pelo Laboratório de Análises de Solos da UTFPR (EMBRAPA, 1997, 2006). A química analítica total foi realizada pelo laboratório LAMIR (UFPR) enquanto o ataque sulfúrico foi realizado pelo Laboratório de Análise de Solos (UFV), e ambas permitem o cálculo dos índices $\mathrm{Ki}$ e Kr, cujos índices permitem inferir o estágio de intemperismo do solo (MONIZ, 1975; IBGE, 2007). As determinações do ferro livre, total e amorfo foram tratadas pelo Laboratório de Solos da Esalq - SP, a partir do método químico de dissolução seletiva utilizando-se oxalato de amônio ( $\mathrm{Fe}_{\mathrm{o}}$ ) e ditionito-citratobicarbonato de sódio (DCB). Posteriormente, determinou-se as razões do ferro, onde 
se estabeleceu a intensidade de intemperismo dos materiais (Fed/Fet), a proporção de óxidos mal cristalizados em relação aos bem cristalizados ( $\mathrm{Fe}_{\mathrm{o}} / \mathrm{Fe}_{\mathrm{d}}$ ) e o estágio de intemperismo dos materiais - $\left(\mathrm{Fe}_{d}-\mathrm{Fe}_{\mathrm{o}}\right)$ / Fe $\mathrm{t}$ (INDÁ JUNIOR \& KAMPF, 2003; TSAI et al., 2007; SILVA NETO et al, 2006; CURI \& KAMPF, 2012; KAMPF et al., 2012).

A mineralogia dos materiais foi realizada pela difração de Raio-X presentes na fração argila, auxiliando na identificação do grau de evolução dos minerais (KER, 1998; RESENDE et al., 2005). As amostras foram determinadas pelo Laboratório de Laminação da Universidade Federal de Viçosa-MG. A mineralogia da fração argila foi realizada a partir dos métodos: a) natural; b) adição de potássio; c) adição de potássio a $350^{\circ}$; d) adição de potássio a 550; e) adição de magnésio e f) adição de magnésio glicolado. Os difratogramas de raios-X foram obtidos através do software "Power X" e para a interpretação dos picos utilizou-se o espaçamento das reflexões de minerais (BRINDLEY e BROWN, 1980). A análise micromorfológica foi realizada para verificar a gênese dos materiais através da identificação dos seus constituintes e dos produtos do intemperismo. A impregnação e confecção das lâminas delgadas foram realizadas pelo Laboratório de Laminação do Instituto de Geociências da USP - São Paulo, ao passo que a interpretação das lâminas ocorreu no Laboratório de Microscopia Ótica da UNIOESTE - Campus Francisco Beltrão, conforme critério e nomenclatura proposto por Stoops (2003).

\section{RESULTADOS E DISCUSSÃO}

\subsection{Atributos físicos e químicos}

O perfil descrito apresentou aproximadamente 10,50 metros de material exposto, constituído por dez volumes de materiais (Figura 2-B), previamente individualizados e descritos por Pontelli et al., (2018). Dos 10 horizontes, 4 correspondem ao solum, 1 à aloterita e 5 à isoalterita. Os materiais do volume superficial, entre 0 a $100 \mathrm{~cm}$, revelam características típicas de horizonte $A$, de acordo com os atributos cor (bruno-avermelhado-escuro) e estrutura, do tipo granular e grau 
fraco (Quadro 1). O volume adjacente, entre as profundidades de 100 a $130 \mathrm{~cm}$, corresponde ao horizonte $A B$, e se mostra semelhante quanto à estrutura, mas diferese pela cor (bruno-avermelhado), indicando horizonte de transição para o horizonte $A$ para horizonte $B$.

Figura 2 - (A) Diagrafia granulométrica; (B) Seção representativa da superfície geomorfológica de Xanxerê (SC)

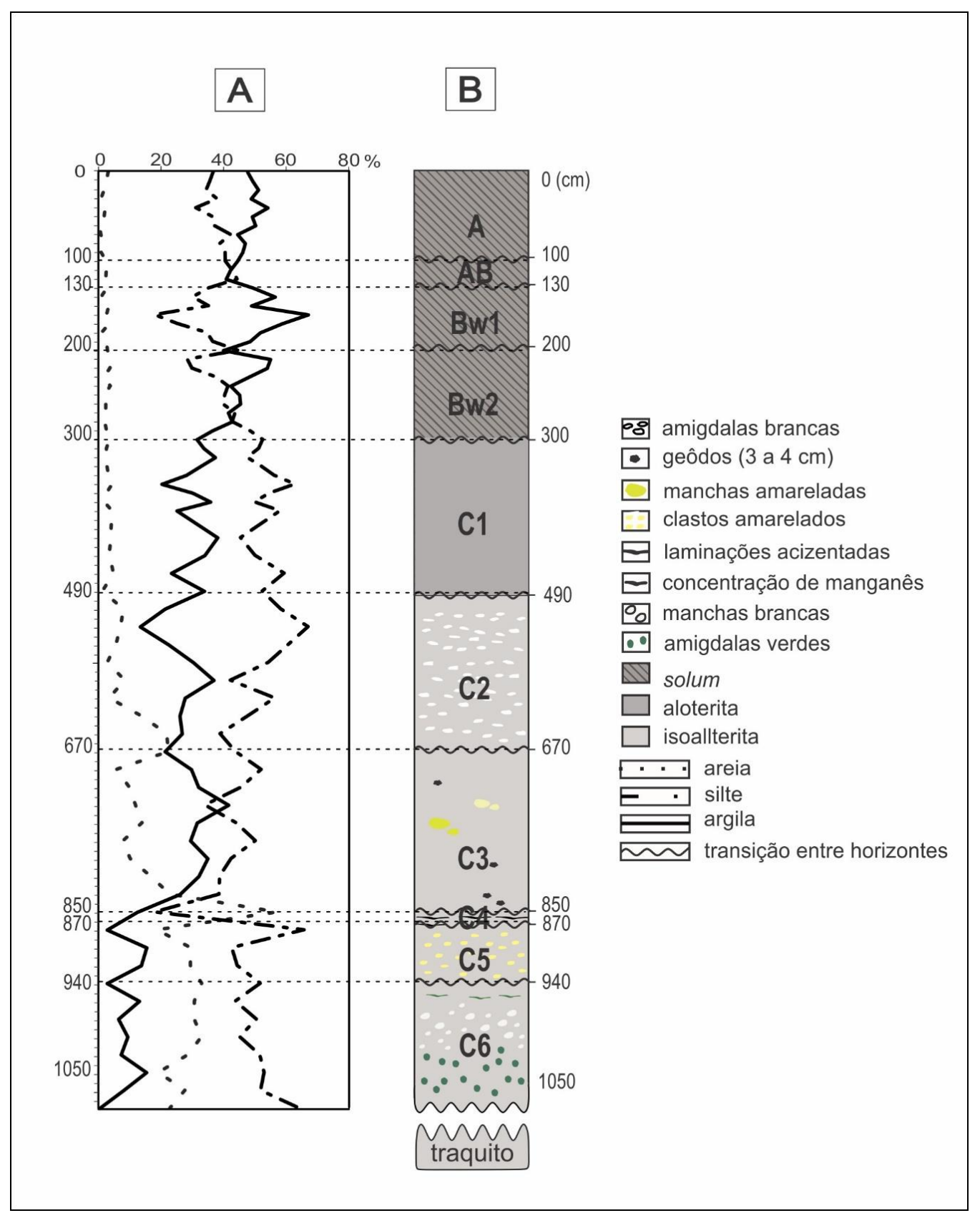

Fonte: Acervo partículas dos autores (2018) 
Entre 130 a 300 cm, identificou-se mudança de estrutura de granular para subangular quando comparado ao horizonte A, com estrutura variando de grau moderado para forte. Esse volume apresentou CTC menor que $17 \mathrm{cmol} / \mathrm{kg}$. Embora a maioria dos atributos desse volume seja semelhante, foi possível estabelecer a divisão em dois horizontes Bw (Bw1 e Bw2) devido a mudança de estrutura, que passa de granular no topo do horizonte Bw1 para blocos subangulares na base do horizonte Bw2, além da média da relação silte/argila, que passa de inferior a 0,6 a superior a 0,6, respectivamente.

A partir da profundidade de 300 cm, até 490 cm, verificou-se considerável aumento da fração silte em relação a fração argila (Figura 2-A). Esse volume corresponde a aloterita, e foi classificado como horizonte C1 (Figura 2-B). Entre as profundidades de $490 \mathrm{~cm}$ até $1050 \mathrm{~cm}$, foram identificados litorelíquias e aumento da fração areia em profundidade, correspondendo a isoalterita (DELVIGNE, 1998). As variações abruptas identificadas pela diagrafia granulométrica permitiram a distinção de 5 horizontes na isoalterita: C2, marcado pela presença de amigdalas brancas e altos teores de argila e silte; C3, caracterizado pela ocorrência de clastos e manchas amareladas e elevados teores de argila e silte; C4, com presença de laminações acinzentadas e aumento significativo da fração areia; C5, caracterizado pela predominância da fração areia sobre as demais e clastos amarelados e C6, caracterizado pela predominância da fração areia, manchas brancas e amigdalas esverdeadas (Figura 2).

A partir da descrição previamente descritas por Pontelli et al. (2018) e análise dos materiais do perfil, e utilizando-se como critério o Sistema Brasileiro de Classificação de Solos (EMBRAPA, 2006), as características obtidas indicam que os materiais sejam típicos de Latossolo Bruno Distrófico, com caráter alítico. 
Quadro 1 - Atributos físicos e químicos: $\mathrm{H}$ : horizontes; Tex: textura; MA: muito argilosa; AS: argilo siltosa; FAS: franco argilo siltosa; Gr: grau; SubA: subangular; Mod: moderada; Cero: cerosidade; Aus: ausente; LD: ligeiramente dura; MF: muito friável; Plast: plasticidade; LPI: ligeiramente plástica; Pega: pegajosidade; LP: ligeiramente plástica; Por: porosidade; MO: matéria orgânica; P: fósforo; K: potássio; Ca: cálcio; Mg: magnésio; SB: soma de bases; CTC: capacidade de troca catiônica; Al: alumínio; V: saturação por bases; m: saturação por alumínio

\begin{tabular}{|c|c|c|c|c|c|c|c|c|c|c|c|c|c|c|c|c|c|c|c|c|c|c|}
\hline \multicolumn{12}{|c|}{ Caracteristicas Fisicas } & \multicolumn{11}{|c|}{ Caracteristicas químicas } \\
\hline \multirow{3}{*}{$\mathrm{H}(\mathrm{cm})$} & \multicolumn{2}{|c|}{ Cor } & \multirow{3}{*}{ Tex } & \multicolumn{2}{|c|}{ Estrutura } & \multirow{3}{*}{ Cero } & \multicolumn{4}{|c|}{ Consistência } & \multirow{3}{*}{\begin{tabular}{c|} 
Por \\
$\%$
\end{tabular}} & \multirow{3}{*}{\begin{tabular}{|c|} 
MO \\
gdm² \\
\end{tabular}} & \multirow{3}{*}{$\mathrm{pH}$} & \multirow{3}{*}{$\begin{array}{c}P \\
m g d m^{2}\end{array}$} & K & $\mathrm{C}_{3}$ & $\mathrm{Mg}$ & SB & CTC & Al & v & $\mathrm{m}$ \\
\hline & \multirow{2}{*}{ Seca } & \multirow{2}{*}{ Úmida } & & \multirow{2}{*}{ Tipo } & \multirow{2}{*}{ Grau } & & \multirow{2}{*}{ Seca } & \multirow{2}{*}{ Úmida } & \multirow{2}{*}{\multicolumn{2}{|c|}{ Molhada }} & & & & & \multirow{2}{*}{\multicolumn{3}{|c|}{$\mathrm{cmol}^{\mathrm{d} d \mathrm{~m}^{3}}$}} & \multirow{2}{*}{\multicolumn{3}{|c|}{ cmolcidm² }} & \multirow{2}{*}{\multicolumn{2}{|c|}{$\%$}} \\
\hline & & & & & & & & & & & & & & & & & & & & & & \\
\hline \multirow{2}{*}{$A p(1-100)$} & \multirow{2}{*}{$\begin{array}{c}2.5 \mathrm{YR} \\
2.5 / 4\end{array}$} & \multirow{2}{*}{$\begin{array}{c}2.5 \text { YR } \\
2.5 / 4 \text { a } 5 \\
\text { YR } 3 / 4\end{array}$} & \multirow[b]{2}{*}{ MA } & \multirow[b]{2}{*}{$\mathrm{Gr}$} & \multirow{2}{*}{ Fraco } & \multirow[b]{2}{*}{ Aus } & \multirow[b]{2}{*}{ Macia } & & & & & 34,85 & 4,40 & 0,05 & 0,08 & 0 & 0,3 & 0,38 & 8,74 & 1,64 & 4,35 & 81,18 \\
\hline & & & & & & & & MF & LPI & LP & 65,68 & 13,40 & 4,60 & 0 & 0,03 & 0,2 & 0,3 & 0.5 & 6,28 & 0,38 & 8,43 & 40,45 \\
\hline$A B(100-130)$ & $\begin{array}{l}5 \mathrm{YR} \\
4 / 8\end{array}$ & $\begin{array}{c}2.5 \mathrm{YR} \\
3 / 4\end{array}$ & AS & \begin{tabular}{l|} 
Gra \\
SubA
\end{tabular} & Mod & Aus & $L D$ & MF & LPI & LP & - & - & - & - & - & - & - & - & - & - & - & - \\
\hline$B w 1(130-200)$ & $\begin{array}{c}10 \mathrm{YR} \\
3 / 8\end{array}$ & $\begin{array}{l}2.5 \mathrm{YR} \\
3 / 4 \text { a } 5 \\
\text { YR } 3 / 4\end{array}$ & MA & SubA & Forte & Aus & LD & MF & LPI & LP & 65.22 & 4,02 & 4,80 & 0,68 & 0,05 & 0,1 & 0,3 & 0,45 & 4,73 & 0,11 & 8,51 & 19,64 \\
\hline$B w 2(200-300)$ & $\begin{array}{c}10 \mathrm{YR} \\
3 / 8\end{array}$ & $\begin{array}{l}2.5 \mathrm{YR} \\
2.5 / 4 \\
\end{array}$ & $\begin{array}{c}\text { MAa } \\
\text { AS }\end{array}$ & SubA & Forte & Aus & LD & MF & LPI & LP & 64,08 & 1,34 & 4,70 & 0,68 & 0,05 & 0,2 & 0,2 & 0,45 & 5,06 & 0,52 & 8,88 & 53,61 \\
\hline C1 topo $(300-410)$ & $\begin{array}{l}5 \mathrm{YR} \\
5 / 4\end{array}$ & 5 YR $3 / 4$ & AS & SubA & Forte & Aus & LD & MF & LPI & LP & 84,32 & 2,68 & 4,50 & 11,72 & 0,05 & 0 & 0,2 & 0,25 & 5,60 & 1,36 & 4,48 & 84,47 \\
\hline $\mathrm{Cl}$ base $(410-490)$ & $\begin{array}{l}5 \mathrm{YYR} \\
5 / 4\end{array}$ & 5 YR 5/4 & AS & SubA & Forte & Aus & LD & MF & LPI & LP & & 1,34 & 4,50 & 1,32 & 0,03 & 0,1 & 0,3 & 0,43 & 7,63 & 2,12 & 5,64 & 83,14 \\
\hline$C 2(480-670)$ & $\begin{array}{c}2.5 \mathrm{YR} \\
3 / 4\end{array}$ & $5 \mathrm{YR} 4 / 4$ & $\begin{array}{l}\text { ThA, AS } \\
\text { eFAZ }\end{array}$ & SubA & Forte & Aus & LD & MF & LPI & LP & - & - & - & - & - & - & - & - & - & - & - & - \\
\hline C3 $(670-850)$ & $\underset{3 / 4}{2.5 \mathrm{YR}}$ & \begin{tabular}{|c|}
$2.5 \mathrm{YR}$ \\
$3 / 4$ a 2.5 \\
YR $3 / 6$
\end{tabular} & $\begin{array}{c}M A a \\
\text { AS }\end{array}$ & SubA & Forte & Aus & LD & MF & LPI & LP & - & - & - & - & - & - & - & - & - & - & - & - \\
\hline$C 4(850-870)$ & $\begin{array}{l}\text { TOYR } \\
3 / 8\end{array}$ & $\begin{array}{l}\text { ToYR } \\
318\end{array}$ & AS & SubA & Forte & Aus & $L D$ & MF & LPI & LP & - & - & - & - & - & - & - & - & - & - & - & - \\
\hline$C 5(870-940)$ & $\begin{array}{c}10 \mathrm{YR} \\
5 / 3\end{array}$ & \begin{tabular}{|c|}
$2.5 \mathrm{YR}$ \\
$2.5 / 4$ a 5 \\
YR $3 / 4$
\end{tabular} & AS & SubA & Forte & Aus & LD & MF & LPI & LP & - & - & - & - & - & - & - & - & - & - & - & - \\
\hline$C 8(940-1050)$ & $\begin{array}{l}5 \mathrm{YR} \\
4 / 4\end{array}$ & 5 YR 4/4 & FAS & SubA & Forte & Aus & LD & MF & LPI & LP & - & - & - & - & - & - & - & - & - & - & - & - \\
\hline
\end{tabular}

Fonte: organização dos autores

\subsection{Caracterização química dos materiais}

O resultado do ataque sulfúrico (Quadro 2) aponta que os valores Ki são menores que 1,9 do topo da seção descrita ao início da aloterita, indicando intensa intemperização dos materiais e sugerindo características cauliníticas, com a presença de argilominerais 1:1 nos minerais secundários (CURI e KAMPF, 2012). A partir da isoalterita até a base da seção, o índice Ki ultrapassa 2,0, apontando que os processos intempéricos não foram tão intensos, indicando argilominerais do tipo 2:1. Já na transição entre os horizontes C6/C7, o valor diminui, equivalendo a 1,96. Em relação ao índice $\mathrm{Kr}$, determinado para os horizontes supracitados, foi identificado valores maiores que 0,75 ao longo de toda a seção descrita, sugerindo presença de materiais cauliníticos (MELLO et al., 2009; CURI e KAMPF, 2012). A química analítica total mostra valores do óxido de ferro que variam entre 27,1 a 35\%, exibindo alta concentração quando comparado aos valores apresentados na rocha. O óxido de 
alumínio apresenta concentração relativa de $100 \%$ em relação a rocha sã, ao passo que o óxido de titânio mostra concentração de nove vezes maiores do que os valores apontados na rocha sã (Quadro 2). Dentre os cátions básicos, verificou-se que os óxidos de cálcio, sódio e potássio foram completamente lixiviados, ao passo que o óxido de magnésio apresenta concentração relativa em relação ao valor encontrado na rocha sã. Em relação ao óxido de silício, percebe-se que houve mais de 50\% de perda (Quadro 2), sugerindo que o processo de hidrólise foi parcial, caracterizando o processo de monossialitização (MELFI e PEDRO, 1977; THOMAS, 1994).

Quadro 2 - Dados do ataque sulfúrico e química analítica.

\begin{tabular}{|c|c|c|c|c|c|c|c|c|c|c|c|c|c|c|c|c|}
\hline \multicolumn{2}{|c|}{ Horizontes } & $A p$ & $\mathrm{AB}$ & $\begin{array}{l}\text { Bw } \\
\text { topo }\end{array}$ & $\begin{array}{c}\text { Bw } \\
\text { base }\end{array}$ & $\begin{array}{c}\mathrm{Cl} \\
\text { topo }\end{array}$ & $\begin{array}{c}\mathrm{Cl} \\
\text { meio }\end{array}$ & $\begin{array}{c}\mathrm{C} 1 \\
\text { base }\end{array}$ & $\begin{array}{c}\mathrm{C} 2 \\
\text { topo }\end{array}$ & $\begin{array}{c}\mathrm{C} 2 \\
\text { base }\end{array}$ & $\begin{array}{c}\mathrm{C} 3 \\
\text { topo }\end{array}$ & $\begin{array}{c}\mathrm{C}_{3} \\
\text { meio }\end{array}$ & \begin{tabular}{c|} 
C3 \\
topo
\end{tabular} & C5IC6 & C6 & Rocha \\
\hline \multirow{6}{*}{$\begin{array}{c}\text { Ataque } \\
\text { sulfurico } \\
(\%)\end{array}$} & $\mathrm{SiO}_{2}$ & 21,27 & 22,4 & 23,74 & 21.11 & - & 28,52 & 30,05 & 28,41 & - & - & 24,42 & 27,3 & 28,4 & - & - \\
\hline & $\mathrm{Al}_{2} \mathrm{O}_{3}$ & 24 & 24,62 & 28,31 & 25,72 & - & 23,88 & 24,47 & 22,82 & - & - & 20,67 & 22,28 & 24,66 & - & - \\
\hline & $\mathrm{Fe}_{2} \mathrm{O}_{3}$ & 24,05 & 24,68 & 24,01 & 26 & - & 27.48 & 26,24 & 25,83 & - & - & 29,75 & 26.41 & 24,13 & - & - \\
\hline & $\mathrm{TiO}_{2}$ & 5,82 & 6,458 & 5,816 & 6,717 & - & 4,83 & 4,945 & 5,083 & - & - & 5,251 & 6.450 & 5,211 & - & - \\
\hline & $\mathrm{Ki}$ & 1,51 & 1,55 & 1,53 & 1,46 & - & 1,89 & 2,00 & 2,12 & - & - & 2,01 & 2,08 & 1,96 & - & - \\
\hline & $\mathrm{Kr}$ & 0,92 & 0,94 & 0,97 & 0,89 & - & 1,09 & 1,24 & 1,23 & - & - & 1,05 & 1,18 & 1.2 & - & - \\
\hline \multirow{17}{*}{$\begin{array}{c}\text { Quimica } \\
\text { Analitica } \\
(\%)\end{array}$} & $\mathrm{FeO}_{3}$ & - & 29,2 & - & 29,4 & 31,5 & 32,5 & 33,6 & 34,3 & 35,7 & 34,3 & 31,8 & - & 27.1 & 35,0 & 4,87 \\
\hline & $\mathrm{SiO}_{2}$ & - & 25,2 & - & 28,5 & 28,7 & 26,6 & 26,1 & 25,3 & 25,4 & 25,5 & 29,0 & - & 28,2 & 24,0 & 84,2 \\
\hline & $\mathrm{Al}_{2} \mathrm{O}_{3}$ & - & 23,4 & - & 23,5 & 22,7 & 21,8 & 21,2 & 20,6 & 19,1 & 19,8 & 20,0 & - & 23.2 & 19,6 & 12,88 \\
\hline & $\mathrm{CaO}$ & - & - & - & - & - & - & - & - & - & - & - & - & - & - & 3,13 \\
\hline & $\mathrm{Na}=\mathrm{O}$ & - & - & - & - & - & - & - & - & - & - & - & - & - & - & 3,45 \\
\hline & $\mathrm{TlO}_{2}$ & - & 6,8 & - & 7,2 & 6,6 & 7,0 & 6,8 & 7,4 & 7,8 & 7.5 & 6,4 & - & 6,1 & 8,0 & 1,6 \\
\hline & $\mathrm{MgO}$ & - & 0,3 & - & 0,3 & 0,3 & 0,3 & 0,3 & 0.2 & 0,3 & 0,2 & 0,3 & - & 0,4 & 0,4 & 0,15 \\
\hline & $\mathrm{P}_{2} \mathrm{O}_{3}$ & - & 0,2 & - & 0,2 & 0,2 & 0,3 & 0,3 & 0,4 & 0,4 & 0,4 & 0,3 & - & 0,4 & 0,5 & 0,46 \\
\hline & $\mathrm{MnO}$ & - & 0,2 & - & 0,3 & 0,3 & 0.2 & 0.1 & 0.2 & 0,3 & 0,3 & 0,2 & - & 1,2 & 0,5 & 0,15 \\
\hline & $K \neq O$ & - & 0,1 & - & 0,1 & - & - & - & - & - & - & - & - & - & 0,1 & 3,94 \\
\hline & $\mathrm{ZrO}_{2}$ & - & 0,1 & - & 0,1 & 0,1 & 0,1 & 0.1 & 0,1 & 0,1 & 0,1 & 0,1 & - & 0,1 & 0,1 & - \\
\hline & $\mathrm{ZnO}$ & - & 0,1 & - & - & - & - & - & 0 & - & - & - & - & - & 0,1 & - \\
\hline & $\mathrm{SO}_{3}$ & - & - & - & - & - & - & 0,1 & - & 0,1 & 0,1 & 0,1 & - & 0,1 & 0,1 & - \\
\hline & CuO & - & - & - & - & - & - & - & - & - & - & - & - & 0,1 & 0,1 & - \\
\hline & P.F. & - & 14,55 & - & 12,57 & 11,67 & 11,68 & 11,49 & 11,58 & 11,02 & 11,71 & 11,65 & - & 13,21 & 11,57 & - \\
\hline & $\mathrm{Ki}$ & - & 1,80 & - & 1,81 & 2,0 & 2,09 & 2,15 & 2,1 & 2,3 & 2,2 & 2,52 & - & 2,1 & 2,1 & - \\
\hline & $\mathrm{Kr}$ & - & 1,01 & - & 1,08 & 1,08 & 1,06 & 1,04 & 1,01 & 1,03 & 1,03 & 1,22 & - & 1,17 & 0,97 & - \\
\hline
\end{tabular}

Fonte: organização dos autores 


\subsection{Distribuição e relações dos óxidos de ferro no solo}

Com relação aos índices do ferro de alta cristalinidade $\left(\mathrm{Fe}_{\mathrm{d}}\right)$, os valores obtidos variam de 10,39 a 14,94\% do horizonte A até o topo do horizonte C3 (quadro 3), indicando teores médios de ferro de alta cristalinidade (TSAl et al., 2007). A partir da base do horizonte C3 até o horizonte de transição C5/C6 os índices diminuem consideravelmente, passando para 8,63 a 5,91 \%, respectivamente (Quadro 3). Os valores do ferro amorfo ( $\left.\mathrm{Fe}_{\circ}\right)$ nos horizontes $\mathrm{A}, \mathrm{AB}$ e Bw1 estão acima de 0,57\%, ao passo que a partir do horizonte Bw2 até o horizonte de transição C5 e C6 os valores são menores que 0,57 \% (Quadro 3), sugerindo que a seção descrita apresenta desenvolvimento laterítico (BECH et al., 1997). Em suma, os materiais estão em avançado estágio de intemperismo no topo e diminuem em profundidade. O ferro total $\left(\mathrm{Fe}_{\mathrm{t}}\right)$ mostra variação entre 17,59 a 25,79 , sendo que a transição entre os horizontes C5 e C6 apresenta o menor índice. Já o maior índice ocorre no horizonte $\mathrm{C} 1$, indicando que nesta profundidade ocorre a maior cristalinidade do ferro (INDA JUNIOR \& KAMPF, 2003).

Quadro 3 - Teores de ferro e suas razões

\begin{tabular}{|c|c|c|c|c|c|c|c|}
\hline \multirow{2}{*}{ Hor. } & \multirow{2}{*}{$\begin{array}{l}\text { Prof. } \\
(\mathrm{cm})\end{array}$} & \multicolumn{2}{|c|}{ Teores de Ferro $(\%)$} & \multicolumn{3}{|c|}{ Razões de Ferro } \\
\cline { 3 - 8 } & $\mathrm{Fe}_{\mathrm{d}}$ & $\mathrm{Fe}_{\mathrm{o}}$ & $\mathrm{Fe}_{\mathrm{t}}$ & $\mathrm{Fe}_{\mathrm{o}} / \mathrm{Fe}_{\mathrm{d}}$ & $\mathrm{Fe}_{\mathrm{o}} / \mathrm{Fe}_{\mathrm{t}}$ & $\left(\mathrm{Fe}_{\mathrm{d}}-\mathrm{Fe}_{\mathrm{o}}\right) / \mathrm{Fe}_{\mathrm{t}}$ \\
\hline $\mathrm{Ap}$ & $50-60$ & 13,49 & 0,65 & 19,89 & 0,048 & 0,678 & 0,645 \\
\hline AB & $100-110$ & 13,38 & 0,70 & 22,4 & 0,052 & 0,597 & 0,566 \\
\hline Bw1 & $160-170$ & 10,39 & 0,83 & 22,18 & 0,079 & 0,468 & 0,431 \\
\hline Bw2 & $250-260$ & 12,01 & 0,46 & 22,47 & 0,038 & 0,534 & 0,514 \\
\hline C1 & $340-350$ & 13,32 & 0,32 & 25,97 & 0,024 & 0,512 & 0,500 \\
\hline C2 topo & $470-490$ & 14,94 & 0,16 & 23,86 & 0,010 & 0,626 & 0,619 \\
\hline C2 base & $570-590$ & 10,62 & 0,10 & 21,23 & 0,009 & 0,500 & 0,495 \\
\hline C3 topo & $670-710$ & 13,12 & 0,19 & 25,79 & 0,014 & 0,508 & 0,501 \\
\hline C3 base & $810-830$ & 8,63 & 0,22 & 23,31 & 0,025 & 0,370 & 0,360 \\
\hline C5/C6 & $930-950$ & 5,91 & 0,52 & 17,59 & 0,087 & 0,335 & 0,306 \\
\hline \multicolumn{2}{|c|}{ Média } & 11,58 & 0,41 & 22,46 & 0,038 & 0,512 & 0,493 \\
\hline
\end{tabular}

Fonte: organização dos autores 
A razão $\mathrm{Fe}_{\mathrm{o}} / \mathrm{Fe}_{d}$ varia ao longo da seção, apresentando valores abaixo de 0,05 nos horizontes A, Bw2, C1, C2 topo e base e C3 topo e base (Quadro 3), sugerindo que estes horizontes apresentam minerais predominantemente cristalinos, comum para materiais de natureza latossólica (INDA JUNIOR e KAMPF, 2003; SILVA NETO, 2006). Os horizontes subsuperficiais $A B$, Bw1 e a transição entre o horizonte $C 5$ e $C 6$ apresentam valores acima de 0,05, indicando minerais mal cristalizados nesses horizontes (TORRENT et al., 1980). Em geral, o valor médio da razão $\mathrm{Fe}_{o} / \mathrm{Fe}_{d}$ dos horizontes analisados foi de 0,03, apontando que a cobertura superficial apresenta, em sua maioria, óxidos de ferro bem cristalizados sobre os não cristalinos. Souza Junior (2003) encontrou valores da relação $\mathrm{Fe}_{\mathrm{o}} / \mathrm{Fe}_{d}$ em torno 0,05 para solos derivados de basalto, no Terceiro Planalto Paranaense.

A razão $\mathrm{Fe}_{d} / \mathrm{Fe}_{t}$ sofre variação entre 0,335 e 0,678 (Quadro 3) e, de modo geral, decai em profundidade, apresentando o maior valor no horizonte A e menor valor na alterita (0,335), na transição entre os horizontes C5 e C6, sugerindo que o intemperismo foi mais atuante nos horizontes superficiais (TORRENT et al, 1980; INDA $J R$, 2002). A razão $\mathrm{Fe}_{d}-\mathrm{Fe}_{o} / \mathrm{Fe}_{\mathrm{t}}$, variando de 0,645 até 0,306 do topo para a base da seção descrita, sugere que a cobertura superficial se encontra em estágio avançado de intemperismo.

\subsection{Mineralogia da fração argila}

A Mineralogia da fração argila foi determinada para os horizontes A, Bw2, C1 (topo), C2 (centro), C1 (Base), C2 (topo), C2 (base), C3, C4, C5 e C6. Para assegurar a identificação dos constituintes, foram interpretados os difratogramas com os diferentes tratamentos em conjunto (Figura 3). As distâncias interplanares foram determinadas pela lei de Bragg e posteriormente foram identificados os constituintes a partir do quadro de padrões apresentados por Brindley e Brow (1980), com apoio dos pressupostos tratamentos apresentados por Resende et al., (2005). 
Figura 3 - Difratogramas de raio-X da fração argila

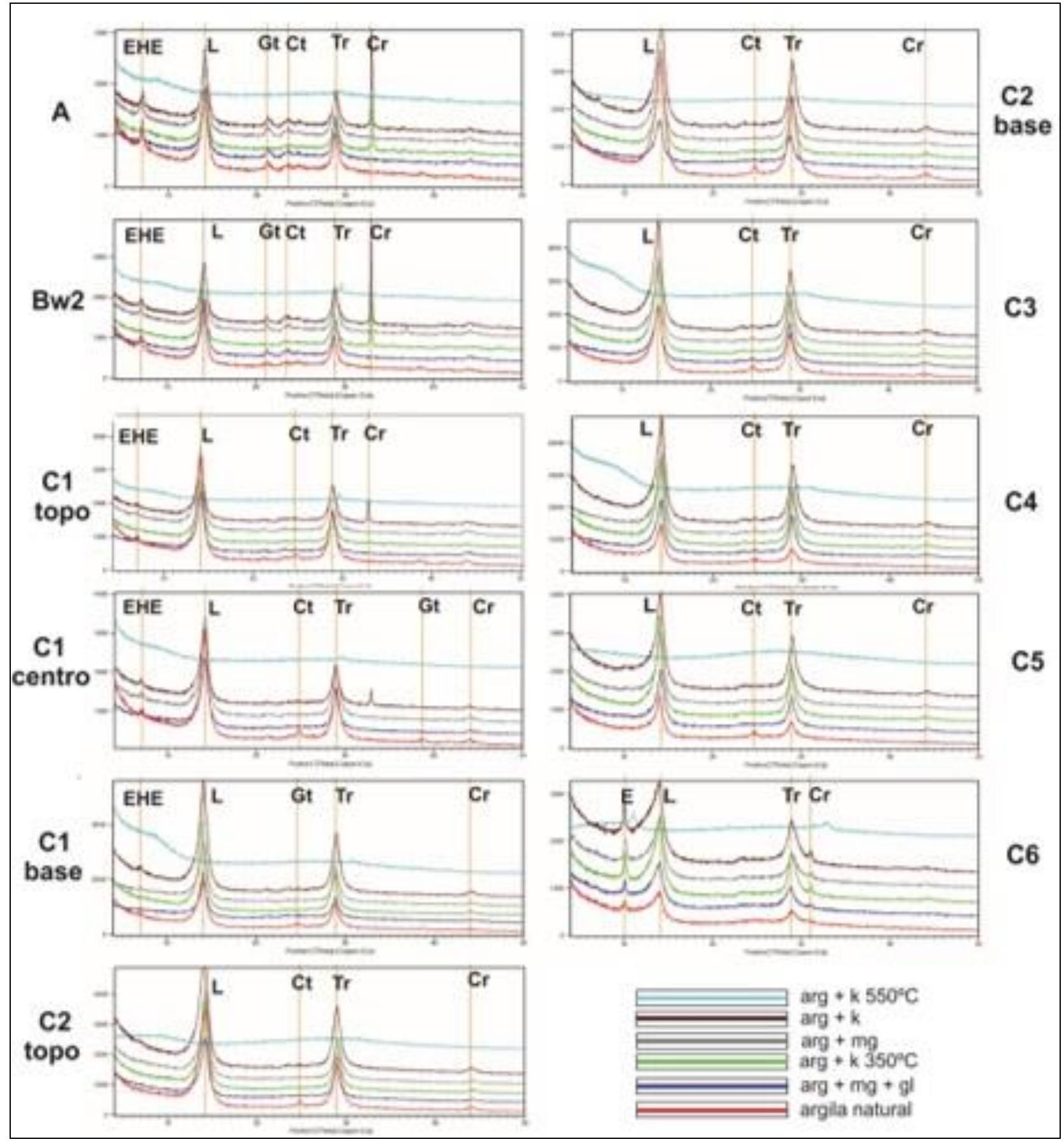

Fonte: organização dos autores

No geral, a mineralogia da fração argila aponta para minerais silicatados (tridimita e cristobalita), filossilicatos (caulinita, vermiculita e esmectita hidróxi-Al entre camadas - EHE), e óxidos de ferro, (lepdocrocita e goethita). Dentre os minerais filossilicatados, percebe-se a presença da caulinita com picos de baixa intensidade em toda a extensão dos materiais, desaparecendo na base da aloterita e na base da 
isoalterita. Essa característica indica caulinita desordenada (RESENDE et al., 2005). Já os minerais EHE ocorrem em toda a extensão do solum (Figura 3). Argilominerais "HE" apresentam, em sua estrutura cristalina, polímeros de Al entre suas camadas, que sugerem o processo de dessilificação parcial, condicionando a caulinitização do solo (KAMPF e KLAMT, 1978). Ainda, a ocorrência de EHE também pode ser responsável pela ausência do óxido de alumínio tipo gibbsita, bastante comum em solos bem intemperizados. Tal fato pode ocorrer pela fixação dos polímeros de Al entre as camadas da EHE, conhecido como "efeito antigibbsitico" (KER e RESENDE, 1990), justificando assim a presença da bohemita e do diásporo (óxidos de alumínio) apenas nas frações areia e silte.

Do ponto de vista pedogeoquímico, não é comum a presença de minerais EHE associados à caulinita (TESKE et al., 2013). Entretanto, Kampf e Klant (1978) sugerem que os argilominerais EHE possivelmente são oriundos de condições ambientais mas frias que atuais, e, uma vez formandos, se tornam bastante estáveis, podendo se manter no solo por longo período de tempo (HARRIS et al. 1988), enquanto a caulinita é tipicamente encontrada em regiões tropicais úmidas sob condições pedoambientais de dessilicificação parcial. Dessa forma, é possível que a gênese da cobertura latossólica esteja associada a diferentes processos pedogeoquímicos, e corresponde a solos poligenéticos (JOHNSON et al., 1990; JOHNSON e WATSON-STEGNER, 1987).

Já em relação aos óxidos de ferro, registra-se goethita em toda a extensão da seção descrita (Figura 3). Não nota-se picos do mineral hematita na fração argila. Sabe-se que condições ambientais subtropicais favorecem a presença de goethita em detrimento da hematita (KAMPF e CURI, 2000), resultando a cor bruno amarelada dos latossolos subtropicais (KAMPF et al., 2012). O óxido de ferro lepidocrocita, que ocorre em todos os horizontes (Figura 3), indica pedoambiente anaeróbico sazonal, formando-se em condições de rápida oxidação. Considerado polimorfo da goethita, é comum sua ocorrência associado a este óxido de ferro (COSTA e BIGHAM, 2009). 


\subsection{Organização micromorfológica}

No horizonte A verificou-se que a distribuição relativa dos constituintes (DRC) é do tipo porfírica aberta, com aproximadamente $45 \%$ de fração fina, $45 \%$ de poros e 10\% de fração grossa, distribuídos no fundo matricial (Figura 4-A). Em relação à fração grossa, sua grande maioria é formada por grãos minerais de tamanho areia muito fina a fina, exibindo forma arestada e distribuídos de forma aleatória, supostamente remetendo a minerais de magnetita/ilmenita. O restante corresponde a grãos de material primário do tipo quartzo, observados sob nicóis cruzados, que são delimitados por suas faces cristalinas, caracterizando material idiomorfo. Com relação a porosidade, em torno de $60 \%$ corresponde a poros cavitários, seguido de cerca de $30 \%$ de empilhamento simples e $10 \%$ de canais. De modo geral, a porosidade é comunicante, sugerindo fortes processos pedogenéticos atuando neste horizonte, possivelmente de caráter biológico. Percebe-se que a micromassa está sendo desmantelada pela abertura de alguns pedes, ocorrendo a desagregação dos pedes em unidades menores (CASTRO, 2008). Nota-se depleção mátrica próximo aos poros, sugerindo que há perda de material devido a circulação da água perto desses locais, possivelmente ferro (Figura 4-A). Com relação à micromassa, a estrutura pédica é fortemente desenvolvida em agregados do tipo granular. A distribuição da micromassa, sob luz polarizada, não se mostra orientada. A cor varia entre 5YR 3/4 (bruno avermelhado escuro e 10R 3/6 (vermelho escuro). Nota-se concentrações de material plásmico em setores do material analisado, exibindo a cor 5YR 3/4 (bruno avermelhado escuro), cuja coloração sugere concentrações de oxihidróxido de ferro (STOLT e LINDBO, 2010). 
Figura 4 -micrografias dos horizontes. A) horizonte A, B) horizonte Bw1, C, D) horizonte Bw2, E, F) C1 topo e base, G) C3 e H) C6
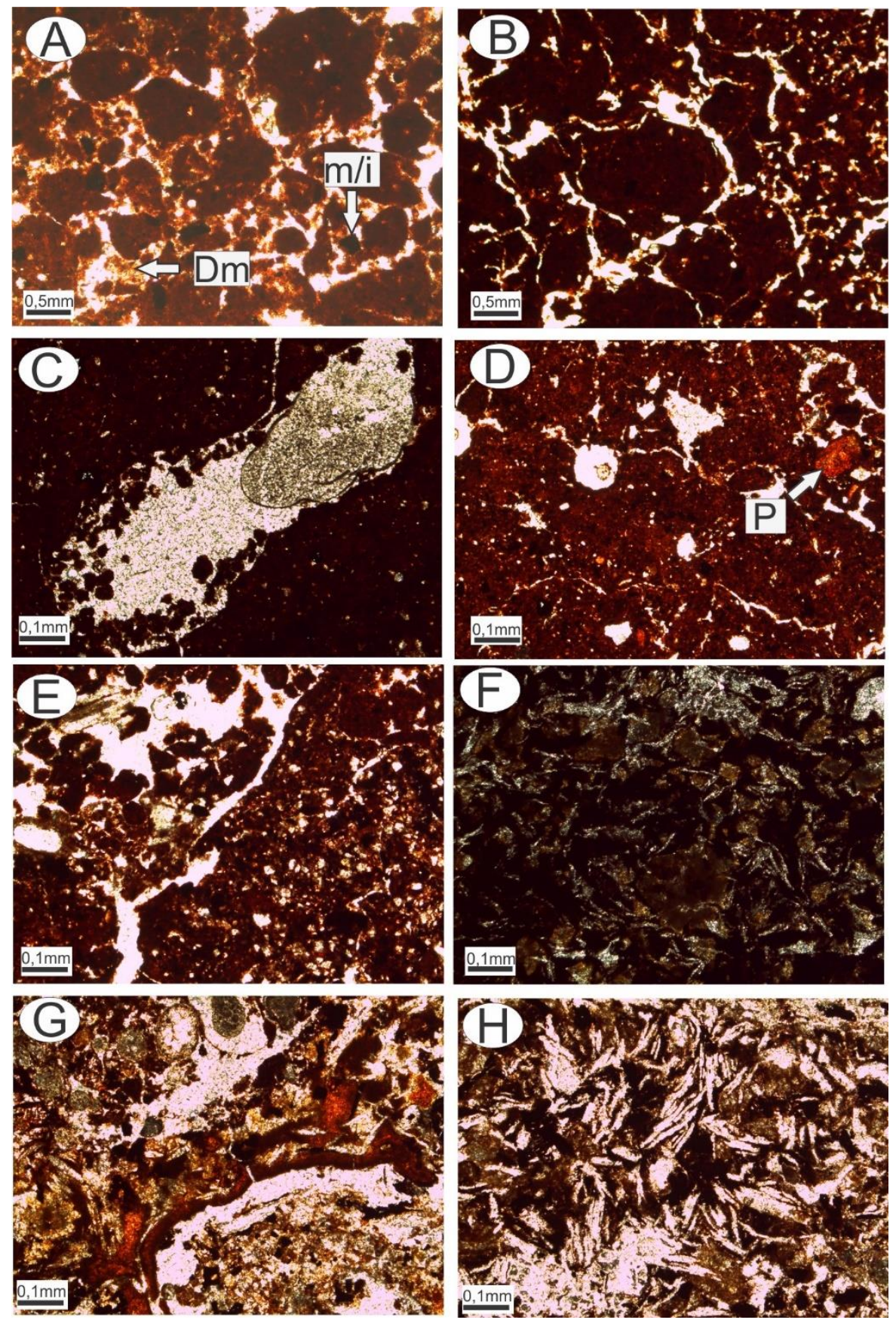

Fonte: acervo particular dos autores (2018)

Os horizontes Bw1 e Bw2 apresentam DCR porfírica aberta, e o fundo matricial apresenta 40\% de fração fina, 20 \% de fração grossa e 40 \% de poros (Figura 4-B, C, D). A fração grossa aumenta em relação horizonte superficial A, sendo composta, predominantemente, por material cujo formato sugere tratar-se de grãos de 
magnetita/ilmenita, de dimensão areia média, forma irregular e distribuídos aleatoriamente. Registra-se presença de pequenos grãos de quartzo que correspondem a litorrelíquias, cerca de 20\%. Em relação a porosidade, 40\% são do tipo vesicular, $40 \%$ cavitários e o restante, fissural. A micromassa apresenta pedalidade moderada em ambos os horizontes.

No geral, a micromassa dos horizontes Bw1 e Bw2 é semelhante. Ambos apresentam pedalidade moderada, embora a microestrutura se difere entre os horizontes. Enquanto a microestrutura no horizonte Bw1 é predominantemente granular, localmente apresentando indícios de estrutura organizada em blocos, no horizonte Bw2 passa a predominar estrutura subangular. É provável que a passagem da água através dos poros fissurais no horizonte Bw1, proporciona a abertura do mesmo, provocando a transformação da microestrutura de blocos subangulares para granulares no horizonte Bw2. Toda a extensão mostra-se distribuída no fundo matricial exibindo cor 2.5YR 2.5/4 (bruno vermelho escuro), com pequenas manchas, sugerindo acumulação de óxidos de ferro.

O horizonte C1 apresenta DRC do tipo porfírica aberta, e o fundo matricial apresenta aproximadamente 50\% de fração fina, 30\% de fração grossa e 20\% de poros (Figura 4-E). A constituição da fração grossa é semelhante quando comparado ao horizonte subjacente, porém os componentes da base do horizonte C1 mudam sutilmente em relação ao material do topo deste horizonte, onde o tamanho e a forma dos minerais que estão se alterando é mais expressiva na base (Figura 4-F). Em relação à constituição, aproximadamente $80 \%$ apresenta feições cujo formato sugere tratar-se de mineral primário do tipo feldspato. O restante da fração grossa, em torno de 20\%, acredita-se ter se formado por grãos de minerais residuais como magnetita/ilmenita, de tamanho areia fina. Em relação a porosidade no horizonte C1, predominam poros cavitários (70\%), que se desenvolvem a partir dos poros fissurais (30\%) e que estão, na maioria das vezes, se desmantelando por completo. A micromassa apresenta pedalidade predominantemente fraca no topo do horizonte C1, em blocos e passa a ser apédica na base. A cor predominante é 5YR 3/4 (bruno 
avermelhado escuro), se mostrando opaca quando analisada sob luz polarizada, provavelmente pela concentração de óxidos de ferro, pontualmente com aspecto variegado pela presença de pequenos grãos de mineral alterados de cor esbranquiçada distribuídos de forma aleatória.

O horizonte C6 é bastante similar ao horizonte C3. Em ambos a DCR é porfírica aberta, cujo fundo matricial é constituído $30 \%$ por fração fina e $70 \%$ por fração grossa, e a porosidade passa a ser ausente (Figura 4-G). Na fração grossa é possível verificar ripas de feldspatos que aparentam estar sob o material plásmico (Figura 4H), sugerindo que o material desse horizonte não está em fase avançada de alteração quando comparado com os materiais do solum. No que diz respeito a micromassa, o material se mostra apédico, não orientado e exibe a cor 5YR 3/4 (bruno avermelhado escuro). Percebem-se manchas de concentração de óxidos de ferro que parecem circundar os minerais que estão sendo alterados. A acumulação de material amarelado e brunado circundando os minerais que estão sendo alterados correspondem à acumulação de óxidos, derivados da composição do material rochoso. As feições do mineral alterado, porém ainda mantendo a forma original, remetem a alteroplasmação (DELVIGNE, 1998).

\section{CONSIDERAÇÕES FINAIS}

Os resultados obtidos pelas análises química, mineralógica e micromorfológica, sugerem que os materiais do solum estão em elevado estágio de intemperismo. Os valores dos dez principais óxidos + zircônio evidenciam que os cátions básicos sofreram intenso processo de lixiviação, com grande parte sendo eliminados do sistema, proporcionando acumulação relativa dos óxidos que possuem baixa mobilidade, entre eles o ferro, alumínio, silício e titânio, sugerindo a ocorrência da hidrólise parcial (monossialitização).

Os índices de intemperismo $\mathrm{Ki}$ e $\mathrm{Kr}$ obtidos confirmam o elevado estágio de intemperismo para o solum, com materiais predominantemente cauliníticos, 
enquanto que a alterita apresenta materiais menos desenvolvidos, constituídos por argilominerais do tipo 2:1. As razões do ferro amorfo apontam que os materiais se apresentam como ferruginoso, transição entre fersialítico e ferralítico (DUCHAUFOUR, 1997). Através da mineralogia da fração argila, confirmou-se a predominância de materiais de natureza ferrífera (magnetita, lepdocrocita, hematita, goethita, ferrihidrita), em conjunto com óxido de alumínio e titânio, embora se destaque a ocorrência de EHE, cuja ocorrência não é comum quando associados à caulinita (TESKE et al., 2013). Nesse sentido, a presença conjunta desses argilominerais sugerem que o material seja de origem poligenética.

Com relação à micromorfologia, a descrição das lâminas delgadas permitiu verificar a intensidade do processo de alteroplasmação na alterita e pedoplasmação no solum. No geral, os materiais que constituem o solum apresentam pedalidade bem desenvolvida, e, em alguns setores, nota-se o desmantelamento dos peds, com a fragmentação da microestrutura em blocos para microestrutura granular, sugerindo que a evolução pedogenética ainda está ocorrendo, principalmente no horizonte Bw2. Esse processo pode ser decorrente da circulação interna da água no solo, visto que os poros estão conectados entre si (LINDBO et al., 2010; STOLT e LINDBO, 2010). Por outro lado, a presenças de poros fissurais, que geralmente são decorrentes da presença de minerais expansivos, também são responsáveis na dessecação dos peds, e formação da estrutura (KOVDA e MERMUT, 2010). Ainda em relação a descrição micromorfológica, a presença da maior quantidade de fração fina sugere que os materiais do solum são mais evoluídos, do ponto de vista morfológico, enquanto que os materiais da alterita estão começando a sofrer processos de intemperismo.

No geral, as análises em conjunto sugerem que os patamares extensos do meio oeste catarinense se enquadram na classe dos Latossolo Bruno Distrófico - caráter alítico. A constituição mineralógica, com a presença de caulinita sugere que o perfil foi submetido a processo de monossialitização, enquanto a ocorrência de EHE sugere o processo de bissialitização. Com base na ocorrência conjunta de tais argilominerais e relacionando com as demais pesquisas já realizadas no contexto regional do Planalto 
das Araucárias, é possível inferir que a cobertura superficial atingiu a fase de monossialitização no Último Interestadial e retornou para bissialitização no Último Máximo Glacial, em decorrência das mudanças climáticas do quaternário tardio, sobretudo nos últimos 25 mil anos antes do presente (MORRÁS et al., 2009; PAISANI et al., 2013). As mudanças das condições ambientais de uma fase mais seca e fria para uma fase mais úmida foram suficientes para modificar parcialmente a estrutura do horizonte $\mathrm{Bw}$, onde o regime hídrico com alternância de umidificação e dessecação provocou o processo de desmantelamento dos peds em estrutura de blocos para granular, mas não modificou o processo pedogeoquímico.

\section{REFERÊNCIAS}

ALMEIDA, B. K. de. Gênese de cobertura superficial em perfil representativo da superfície geomorfológica de Chapecó - Planalto das Araucárias. 2017.126 f. Dissertação (Mestrado em Geografia) - Universidade Estadual do Oeste do Paraná, Francisco Beltrão, 2017.

BECH, J.; RUSTELLET, J.; GARRIGÓ, J.;TOBÍAS, F. J.; MARTÍNEZ, R. The iron contente of some red mediterranean soils Spain and pedogeonic significance. Catena., n. 28, p. 211-229,1997.

BERTUOL, E. C Estágio de Intemperismo da Cobertura Superficial na Superfície Geomorfológica V (Clevelândia/PR) - Planalto das Araucárias. Dissertação (Mestrado em Geografia) - Universidade Estadual do Oeste do Paraná, Francisco Beltrão, 2013.

BRONGER, A.; CATT, J. A. Summary outline and recommendations on paleopedological issues. Department of Geography, Quaternary International, p 5-16, Gemany, 1989.

BRINDLEY, G.W.; BROWN, G. Crystal structures of clay minerals and their X-ray identification. London: Mineralogical Society, 1980, 495p.

CALDASSO, A. L. da S., VIERO, A. P., FREITAS. M. A. Capítulo 3: geologia. In.: Diagnóstico de recursos hídricos subterrâneos do oeste do Estado de Santa Catarina - Projeto Oeste de Santa Catarina. Porto Alegre: CPRM/SDM-SC/DAS-SC/EPAGRI. 2002.

CASTRO, S.S. Micromorfologia de solos - bases para descrição de lâminas delgadas. Goiânia. 2a Edição. UNICAMP/UFG, 2008, 131p. 
COSTA, A.C.S.; BIGHAM, J.M. Óxidos de Ferro. In: MELO, V.F. \& ALLEONI, L.R.F. Química e Mineralogia do Solo - Parte 1: Conceitos Básicos. Viçosa: SBCS, 2009, p. 505-572.

CURI, N. e KAMPF, N. Caracterização do solo: In: Ker, J.C et al., (Edits) Pedologia: fundamentos. Viçosa: SCBS, 2012, p 147 - 170.

DAL-BERTI, WANESSA SUELEN PELOSO. Caracterização de perfis de intemperismo entre as superfícies geomórficas V e II - Planalto das Araucárias. Dissertação (mestrado em geografia) - Universidade Estadual do Oeste do Paraná, 2015

DELVIGNE, J. E. Differentiation of the alterites. In: Delvigne, J. E. Atlas ofmicromorfology of mineral alteration and weathering. Canadá: mineralogical association of Canada and Orstom Editions, 1998.

DUCHAUFOUR, P. Abrangé de pedologic sol environnment. Masson, p. 154/221, 1982.

EMBRAPA. - Empresa Brasileira de Pesquisa Agropecuária. Centro Nacionalde Pesquisa de Solos. Manual de métodos de análise de solos. 2.ed. Rio dejaneiro: Ministério da Agricultura e Abastecimento, 1997. 212p.

EMBRAPA. - Empresa Brasileira de Pesquisa Agropecuária. Centro Nacional de Pesquisa de Solos. Sistema brasileiro de classificação de solos. 2.ed. Rio de Janeiro: EMPRABA-SPI, 2006, 206 P.

GASPARI, M. C. Grau de evolução pedogeoquímica da superfície geomorfológica de Xanxerê (SC) - Planalto das Araucárias. 2017. 111 f. Dissertação (Mestrado em Geografia) - Universidade Estadual do Oeste do Paraná, Francisco Beltrão, 2017.

HARRIS, W. G.; HOLLIEN, K. A.; YUAN, S. R.; BATES, S. R. ACREE, W. A. Nonexchangeable potassium associated with hydroxy-interlayered vermiculite from coastal plain soils. Soil Science Society of america journal, v. 52, pg. 1486-1492, 1988

INDÁ JUNIOR, A. V. Caracterização de goethita e hematita em solos poligenéticos. Tese (Doutorado em Ciência do Solo). Universidade Federal do Rio Grande do Sul Faculdade de Agronomia, Porto Alegre, 2002.

INDÁ JUNIOR, A. V.; KAMPF, N. Avaliação de procedimentos de extração dos óxidos de ferro pedogênicos com ditionito-citrato-carbonato de sódio. Revista Brasileira de Ciência do Solo, n²7, p.1139-1147, 2003.

INDÁ JUNIOR, A. V; KAMPF, N. GIASSON, E.; SILVA, J. A. L. da. Cinética da dissolução redutiva da goethita e hematita em solos poligenéticos. Revista Ciência Rural, V. 35, N. 3, P. 553-561, mai-jun, 2005.

IBGE. Instituto brasileiro de Geografia e Estatística. Manual técnico de pedologia, 2.ed. Rio de Janeiro, 2007. 
IBGE. Instituto brasileiro de Geografia e Estatística. Manual técnico de vegetação. Rio de Janeiro, 2012.

JOHNSON, D.L.; WATSON-STEGNER, D. Evolution Model of Pedogenesis. Soil Science, v.143, p. 349-366, 1987.

JOHNSON, D.L.; KELLER, E.A.; ROCKWELL, T.K. Dynamic Pedogenesis: New views on some key soil concepts and a model for interpreting quaternary soils. Quaternary Research, v.33, p.306-319, 1990.

KAMPF, N.; KLAMT, E. Mineralogia e gênese de Latossolos (Oxisols) e solos podzólicos da região nordeste do Planalto Sul-Rio Grandense. Revista Brasileira de Ciências do Solo, v. 2, p. 68-78, 1978.

KAMPF, N.; CURI, N. Óxidos de ferro: indicadores de ambientes pedogênicos. In: NOVAIS, R.F.; ALVAREZ, V.H.; SCHAEFER, C.E.G.R. Tópicos em Ciência do Solo. Viçosa, M, v.3, p $1-54,2000$.

KAMPF, N.; MARQUES, J.J.; CURI, N. IV - Mineralogia de solos brasileiros, p.81-145. In: KER, J.C.; CURI, N.; SCHAEFER, C.E.G.C.; TORRADO, P.V. Pedologia: Fundamentos. Viçosa. MG, SBCS, 343p. 2012.

KER, J. C. Latossolos do Brasil: uma revisão. Geonomos. n. 5, p. 17-40, 1998.

KER, J. C.; RESENDE, M. Caracterização química e mineralógica de solos brunos subtropicais do Brasil. Revista brasileira de Ciências do Solo. 14:215-225, Campinas, 1990.

KOVDA, I. \& MERMUT, A., Vertic features. In Stoops, G., Marcelino, V. \& Mees, F. (eds.), Interpretation of Micromorphological Features of Soils and Regoliths. Elsevier, Amsterdam, pp. 109-127, 2010.

LINDBO, D.; L., SCOLT, M. H.; VEPRASKAS, M. J. Redoximorphic Features. In: STOOPS, G.; MARCELINO, V.; MEES, F. (Eds.). Interpretation of micromorphological features of soils and regoliths. Amsterdam: Elsevier, p. 129-147, 2010.

MANFREDINI, L. Gênese do relevo entre Serra da Fartura e Rio Chapecó - Planalto das Araucárias: o caso da superfície geomorfológica de Abelardo Luz (SC). Dissertação (Mestrado em Geografia), Universidade Estadual do Oeste do Paraná - Francisco Beltrão, 2016,118p.

MELFI, A. J.; PEDRO, G. Caracterização e repartição dos principais tipos de evolução pedogeoquímica. Revista Brasileira de Geociências. V. 7, p. 271- 286, 1977. 
MELFI, A.J.; PEDRO, G.; VOLKOFF, B. Gênese, morfologia e classificação do solo natureza e distribuição dos compostos ferríferos nos solos do Brasil. V.5, Revista Brasileira de Ciências do Solo. 3: 47 - 54, 1979.

MELLO, V.F.; CASTILHOS, R.M.V.; PINTO, L.F.S. Reserva mineral do solo. In: MELLO, V.F. e ALLEONI, L.R.F. Química e mineralogia do solo. Parte I - conceitos básicos. SBCS, Viçosa, 2009, pg. $251-332$.

MENDONÇA, F., DANNI-OLIVEIRA, I. M. Climatologia: noções básicas e climas do Brasil. São Paulo. Oficina de textos, 2007.

MONIZ, A.C. Elementos da pedologia. Rio de Janeiro: Livros técnicos e científicos, 1975.

MORRÁS, H., MORETTI, L., PÍCCOLO, G., ZECH, W. Genesis of subtropical soils with stony horizons in NE Argentina: Autochthony and polygenesis. Quaternary international, v. 196, pg. 137-159, 2009

NARDY, A. J. R., MACHADO, F. B., OLIVEIRA, M. A. F. As rochas vulcânicas mesozíocas ácidas da Bacia do Paraná: litoestratigrafia e considerações geoquímico estratigráficas. Revista Brasileira de Geociências. 38(1) p. 178 - 195. UNESP, São Paulo, 2008.

PAISANI, J.C.; GEREMIA, F. Evolução de encostas no Planalto Basáltico combase na análise de depósitos de colúvio - médio vale do rio Marrecas, SW doParaná. Geociências, UNESP, v. 29, p.321-334, 2010.

PAISANI, J. C., PONTELLI, M. E., ANDRES, J. Superfícies aplainadas em zona morfoclimática subtropical úmida no Planalto basáltico da bacia do Paraná (SW Paraná/NW Santa Catarina. Primeira aproximação. São Paulo, UNESP, Geociências, v.27, n.4, p 541-553, 2008.

PAISANI, J. C., PONTELLI, M. E., CALEGARI, M. R. Evolução de bacias de baixa ordem hierárquica nos 41.000 anos AP - Brasil Meridional. Mercator, Forteleza, v.11.n26. p 131-148, 2012a.

PAISANI, J.C.; PONTELLI, M.E.; CORREA, A.C.; RODRIGUES, R.A.R. Pedogeochimistry and micromorphology ox oxisols - a basic for understanding etchplanation in the Araucarias Plateau (Southen Brazil) in the Late Quaternary. Journal of South American Earth Sciences. Vol 48, p. 1-12, 2013.

PAISANI, J.C.; PONTELLI, M.E.; CALEGARI, M.R. Contribuição para a reconstrução de paleosuperfícies de alteração no Planalto de Palmas/Água Doce - Sul do Brasil. Geographia, ano 17, n 34, p. 221-242, 2014. 
PELUSO JUNIOR, V. A. O relevo do território catarinense. Geosul, n 2, UFSC, p. 1 - 63, 1986.

PONTELLI, M. E.; MANFREDINI, L.; OLIVEIRA, D. M. R.; CAVAZINI, A.Natureza da cobertura superficial ao longo de patamares dissecados entreSerra da Fartura (PR/SC) e rio Chapecó (Abelardo Luz/SC) - Planaltodas Araucárias: Primeira aproximação. Revista Equador (UFPI), Vol. 4, nº 3.Edição Especial XVI Simpósio Brasileiro de Geografia Física Aplicada.Teresina, Piauí. p. 346-351. 2015.

PONTELLI, M. E. ; GASPARI, M.; PAISANI, J. C. ; OLIVEIRA, D. R. M. . Grau de alteração da cobertura superficial em patamares extensos na superfície geomorfológica de Xanxerê - Planalto das Araucárias, sul do Brasil.. In: XII Simpósio Nacional de Geomorfologia - Paisagem e Geodiversidade: A valorização do patrimônio Geomorfológico Brasileiro, 2018, Crato. Anais do XII SINAGEO, 2018.

RESENDE, M.; CURI, N.; KER, J. C.; REZENDE, S. B. Mineralogia de solos brasileiros: interpretação e aplicações. Lavras: Editora UFLA, 2005.

RITTMANN, A. Stable Mineral Assemblages of Igneous Rocks - A Method of calculation. Springer - Verlag Berlin, Heidelberg, 1973.

RODRIGUES, R. A. Estágio de intemperismo de perfil laterítico em área subtropical com substrato basáltico - superfície aplainada VI (SW PR). Dissertação (Mestrado em Geografia) - Universidade Estadual do Oeste do Paraná, Francisco Beltrão, 2010.

SANTOS, R.D. dos., LEMOS, R.S. de., SANTOS, H.G. dos., KER, J.C., ANJOS, L.H.C. dos., SHIMIZU, S.H. Manual de descrição de coleta e solo no campo. $5^{a}$ Edição. Viçosa, 2005.

SILVA NETO, L. F. Óxidos de ferro, matéria orgânica e adsorção de fósforo em dois Latossolos sob diferentes sistemas de manejo, 2006. Dissertação de Mestrado Universidade Federal do Rio Grande do Sul, Porto Alegre, RS. 2006.

SOUZA JUNIOR, I. G. de. Mineralogia da fração argila e a distribuição de elementos traço associados aos óxidos de ferro do horizonte B de solos do estado do Paraná, 2003. Tese de Doutorado - Universidade Estadual de Maringá, Maringá.

STOLT, M.; LINDBO, D. L. Soil organic matter. In: STOOPS, G.; MARCELINO, V.; MEES, F. (Eds). Interpretation of micromorphological features of soils and regoliths. Amsterdam: Elsevier, p. 369-396. 2010.

TSAI, $H$. Pedogenic correlation of lateritic river terraces in central Taiwan.Geomorfology. Science Direct. P. 201 - 213, 2007.

TESKE, R.; ALMEIDA, J. A.; HOFFER, A.; NETO, A. L. Caracterização mineralógica dos solos derivados de rochas efusivas no Planalto Sul de Santa Catarina, Brasil. Revista de Ciências Agroveterinárias, Lages (SC), v.12, n.2, p.187-198, 2013. 
THOMAS, M.F. The alteration of rocks under tropical conditions, In: THOMAS, M.F. Geomorphology in the Tropics, 1994. P.19-83.

TORRENT, J.; SCHWERTNABB, U.; SCHULZE, D. G. Iron oxide mineralogy of some soils os two river terrace sequences is spain. Geoderma, n²3, p. 191-208, 1980.

VOLKMER, S. Mineralogia e morfologia de coberturas de alteração desenvolvidas em rochas vulcânicas ácida: os exemplos de Palmas e Pinhão, PR. Tese (Doutorado em Geoquímica e Geotectônica). Instituto de Geociências, Universidade de São Paulo, São Paulo. 1999. 184 pg. 